\title{
Ethical Issues and Politics in Research for Sustainable Resource Management in Tanzania
}

\author{
Evaristo Haulle \\ University of Dar es Salaam, Dar es Salaam, Tanzania
}

\begin{abstract}
Understanding Research ethics is the key for producing sound findings to guide management of resource in any community. Through in-depth interview, observation and documentary search, it was noted that most of the studies are not self-driven and lack ethical integrity. People are hired to produce report without clear and streamlined methodology. Nature of the community and the way it is organised poses challenge in acquiring information. In principle, culture of the people to expression is an important aspect in getting liable findings. The conflicts over resources in Namawala and Magaiduru villages have led to the loss of trust and rejects on researchers as they are discovered to provide villagers with false information. Some findings are fabricated to convince the donors' interests to call for more funds for personal interests. Other decision makers would commission researcher to produce false data to suit their interests. This causes academic and researchers being classified as a tool of politician to pacify the public in order to maintain the status quo. The problem is caused by lack of sufficient research fund and understanding on the research essence, and importance of ethical consideration for good research. The situation causes multiple sided effects in the community. Generally, lack of research ethics and presence of greed politicians jeopardise resource management, peace and security. There is need to build the culture of truth and integrity for community development. Research methods need to be taught rigorously in order to build capacity in tools and principles.
\end{abstract}

Keywords: research ethics, politics, sustainable development

\section{Introduction}

Tanzania is rich in natural resources, such as mountains, forests, wetlands, wildlife, minerals, fresh and saline water bodies, fisheries and many others (URT, 1997; 1998). The resources are not only providing aesthetic value, but also they are the base for community livelihood and wellbeing. Most of these resources are at risk and some are depleted due to limited and inappropriate management measures (URT, 1998; Moshy, 2006). Research is required in order to improve condition of the society directly or indirectly. This should go hand in hand with justification of the relevancy of the study. If that cannot be justified, it is wastage of time of both researcher and respondents (Kumar, 2012).

According to John Mill, "mentality" is necessary, in order to promote autonomy of the person. A person cannot be forced to be good and the state should not dictate the kind of life a citizen should lead; it would be better for citizen to choose badly than for them to be forced by the state to choose well (Denzin \& Lincoln,

Evaristo Haulle, Ph.D., lecturer, Mkwawa University College of Education (MUCE), University of Dar es Salaam.

Correspondence concerning this article should be addressed to 2284 Iringa, Tanzania, East Africa. E-mail: haulledict@muce.ac.tz / haulledict@gmail.com. 
2013). In this regard, peer review process is said to be the best in guaranteeing of an unbiased research findings (Iphofen, 2011).

Research is more than skills; it examines critically various aspects of life, the understanding and formulation of guiding principles that govern a particular procedure and developing and testing new theories that contribute to the advancement of profession and human life (Kumar, 2012). It is a habit of questioning what is existing and finds explanation for what is perceived with a view of instituting appropriate change for effective social practice and/or knowledge/theory development. In this case, therefore, sustainable management of natural resource depends much on the nature of research findings in relation to policies and political setting of the society.

Research is an evidence-based practice and a way of collecting accurate and reliable information about a phenomenon for shaping the thinking and practice. In this regard, scientific ways of attaining information, questioning and analysing the findings to obtain an indubitable conclusions is important for sustainable development of resources, livelihood and human kind.

Any research is being undertaken within a frame work of a set of philosophies. It uses procedures and techniques that are valid and reliable, thus, it is designed to be unbiased and objective (Kumar, 2012). Material circumstances play a fundamentally determining role in shaping ideas as human beings attempt to reflect in thought the world around them (Wills, 2002). However, when humans produce those reflections of the world, they go on to act in ways that are informed by the ideas they hold. While Marx stresses the fundamental role of the external world and of material circumstances in determining consciousness, he also points out that in changing their circumstances, human beings also produce the basis for further intellectual development. Human beings, interacting with their environment through the labour process, transform their own existence and thereby also transform their consciousness. It is also evidenced by the idealism that the society is the result of the ideas and thus what exist in the society if the reflection of the abstract. So it determines which philosophical underpinning that the study is taken though all of them should have coherence and methodology to reach to a scientific conclusion. Social research takes place in social context. Therefore, social research must take into account many ethical and political issues alongside scientific issues in designing and executing research (Babbie, 2005).

\section{Methodology}

The paper focuses on two areas which are Ngorongoro and Kilombero districts in Tanzania. Ngorongoro has been taken, because it is among cases that deal with land resource conflicts in relation to wildlife conservation and human livelihood nexus. Ngorongoro district is located in Arusha region Northern Tanzania. It has Serengeti National Park, Loliondo Game Controlled Area (LGCA) and Ngorongoro Conservation Area (NCA) which is the World heritage site and the Biosphere Reserve (Haulle, 2014). Kilombero district was selected and involved in the study, because it is a very fertile valley in the Rufiji basin. It is highly involved in agriculture. The main case is drawn from Namawala village where research and politics intertwined.

Primary data were obtained through in depth interviews and observation. The techniques had power to provide inner understanding of the matter in the community. The techniques were employed to capture information relating social pattern and resource conflicts in relation to research. Documentary review was employed to obtain secondary data that supplemented the primary data collected. Further, the existing situation was also reviewed through social and mass media. 


\section{Findings and Discussion}

\section{The Nature of the Community and Its Organisation}

The culture of the community, the level of understanding of the phenomena within the community governs the decision making and ways to act on the matter (Haulle, 2014). Therefore, the nature of the community and its organization is very important in order to attain credible findings. Some of the cultural settings without prejudice or knowledge of the researcher and without bad intention of the respondent, the information provided may be wrong. For instance, the study found that the Maasai do not count individual cattle.

When a Maasai has 80 cows he may say he has six cows. In saying so he means that all 80 cows results from six cows. We do not count the off-spring, but we identify the off spring through their parents. This also applies to goats and sheep counting.

Similar situation is experienced in human population census.

My friend, the Maasai have no tradition of counting people. We just mention the names of people involved in the event although with modernity some do. Depending on the nature and your approach in some cases you may get an exaggerated value... But also the value may be minimized at the time anticipating revenue charges. Generally, we give birth to many children.

Basing on these findings, it is questioned that to what extent the population census or livestock survey considered such anomalies in obtaining reliable and sound data. Furthermore, it was revealed that when there is a crisis like when a community faces a disaster, and so calling for provision of relief the number to be provided will be exaggerated. On the other hand, when counting is done for the purpose of estimating revenue/tax, the number provided decreases. In this situation, the accuracy and liability of data cannot be clearly captured; and, therefore, the research findings could not be useful in planning and decision making for sustainable resource utility and enhancement. It is clearly stated that the accuracy of data is a cardinal principle of research (Denzin \& Lincoln 2013). In this way, a researcher needs to be creative in order to obtain real data that will meet purpose of the research conducted.

In the process of attaining consent, there is a need to create a strong relationship between the researcher and respondent (Iphofen, 2011). This is important in order to build confidence of respondent to researcher. It was further found out that the Maasai women were not willing to speak to men especially who is not a Maasai "Ndorobo" or "Olmek". It was noted that Maasai women can express freely to another women than a man. Contrary to this, most of the questions asked were answered by "No" or "Not aware". Such responses may influence finding while they represent neither reality nor perceptions of the respondents. The main question is that: Are the researchers committed themselves in understanding the nature of the community before undertaking research? The study found that most of the researchers are focusing on the specific information related to their study. In this case, attaining the truth that would be barred by the cultural setting would not be resolved; hence, the liability of data at stake.

\section{Ethics and Corruption in the Community}

Ethics and politics are related in research though they are different. Ethics of social research deals mostly with the methods employed in undertaking the research (Babbie, 2005). Political issues on the other hand tend to emphasis on the substance and use of research. It is clear that there are no formal codes of accepted political conduct, even though some ethical norms have political aspects (Bryman, 2004; Babbie, 2005). The experience 
has shown that some researchers put themselves in position where they take part in research. Generally, there is accepted view that personal political orientation should not interfere with or unjustifiably influence scientific research. It is improper for a researcher or a commissioned researcher to use shoddy techniques to distort or lie about his or her research as a way of furthering the researcher's political views (Babbie, 2005).

Data collection is one of the important activities that is done in order to reach to rational conclusion. A lot of issues are raised on this activity. One could ask why I should provide information. What will I get in the process of informing the researcher? Is it right to disturb a person in order to get information? If such questions and attitude were adopted, the progress and development in natural resource and other spheres of living could not be attained (Kumar, 2012). Proper handling of quality research, therefore, requires a researcher to justify means and end together.

The politics in research depends on the integrity of community itself. In some cases the respondents can convince researcher. That they know everything and nobody else will tell you new things. This is justified by the observation done in Nayobi where the village chairperson commented that,

The researcher! What we have answered is more than enough. I as the chairperson of this village can assure you that no one will give you other answers than these, therefore, there is no need for you to interview all people in the list.

It should be noted that sometimes what respondents said was logical and real. Haulle (2014) showed that whatever the Laigwanan speaks within the Maasai community would be adhered by all members. This was revealed when the Regional Commissioner of Arusha region renounced the existence of Nayobi, the Ward Councillor who was also a laigwanan of seuri age group provided a short speech, cried and left the meeting. After this all villagers in the meeting left and followed him while leaving the regional commissioner with his delegates alone without audience (Haulle, 2014). It should be not however that, research methods planned were not fulfilled properly and scientific enquiry could be at trial.

One of the cardinal principles of research ethics is to protect the respondents. Respondents should not be harmed in any form-weather psychologically or physically (Mwanje, 2001; Iphofen, 2011). It was revealed that when the researchers continued with the study, most of the people denied to respond and a few others who accepted to respond did not provide true information. Later, it was noted that the study was sensitive to them, and thus they were not ready to vacate the area as the government ordered them previously. In this situation, researchers were seen as arm of the state. It was noted that giving the researchers true information relating to the severity of the disaster could lead them to relocation. This implies that the respondents must have been harmed by research in one way or another in the past.

This situation terrified the research assistants who were identified from Nayobi village in Ngorongoro. These assistants had to stop supporting research in a fear of getting revenge from other people within the community. In the same village, the researchers were advised to save time and money by fabricating the data.

Why don't you give us a token, so as we can help you to fill all the questionnaire very fast, by the way I am a chairman of the village, no one will give you a different answer .... This is what others do and they are successful.

This clearly shows that members of the community do not know the essence of research. It may be due to the expected or previous harm that the community experienced, the chairman was diplomatic to researcher that let him fill the forms in a way that the village would not be harmed once again. And if the statement was genuine, it means that most of the researchers working in this area are unethical. In this circumstance, violation 
of the research ethics does not mean anything to the community and researcher in general. Such unrealistic studies cannot be useful in planning and management of resources.

The community accepted the fabrication of research. To date, there are many people and organs that are freely marketing themselves that they can write thesis/dissertation of different subjects without following a systematic and logical framework of the process (Figure 1). Yet when these works are presented in academic finding is unpublished, and they cannot be used for development purpose. In fact, they have added no knowledge in body of literature.

It was also noted that the "thesis writing experts" charge between Tsh. 1,000,000 to 3,000,000/= (Equivalent to USD 750-2000). It was found out through the interview that masters dissertation can be written to a price up to $1,500,000 /=$ while Ph.D. thesis/dissertation can be written with the payment that ranges between $1,500,000$ to $3,000,000 /=$. It was revealed that the "experts" do ask their customers whether they needed a full work from the data cooked to the thesis/dissertation writing or just data analysis and report/dissertation writing. The price depends on the nature of the study, bargaining power and whether you have given them data or not. The researcher of the current study has been approached by three students from different universities with intention of commissioning him with dissertation writing. The post in Figure 1 was taken in Mnazi moja area, such post are available in most of the universities including University of Dar es salaam main campus, Open University of Tanzania, Mzumbe University and Institute of Financial Management.

It is clear that some of the researchers are not aware of research ethics that will need to be adhered. In this case, their violation results from ignorance, though their adverse impacts are similar to those who did it intentionally and those out of ignorance.

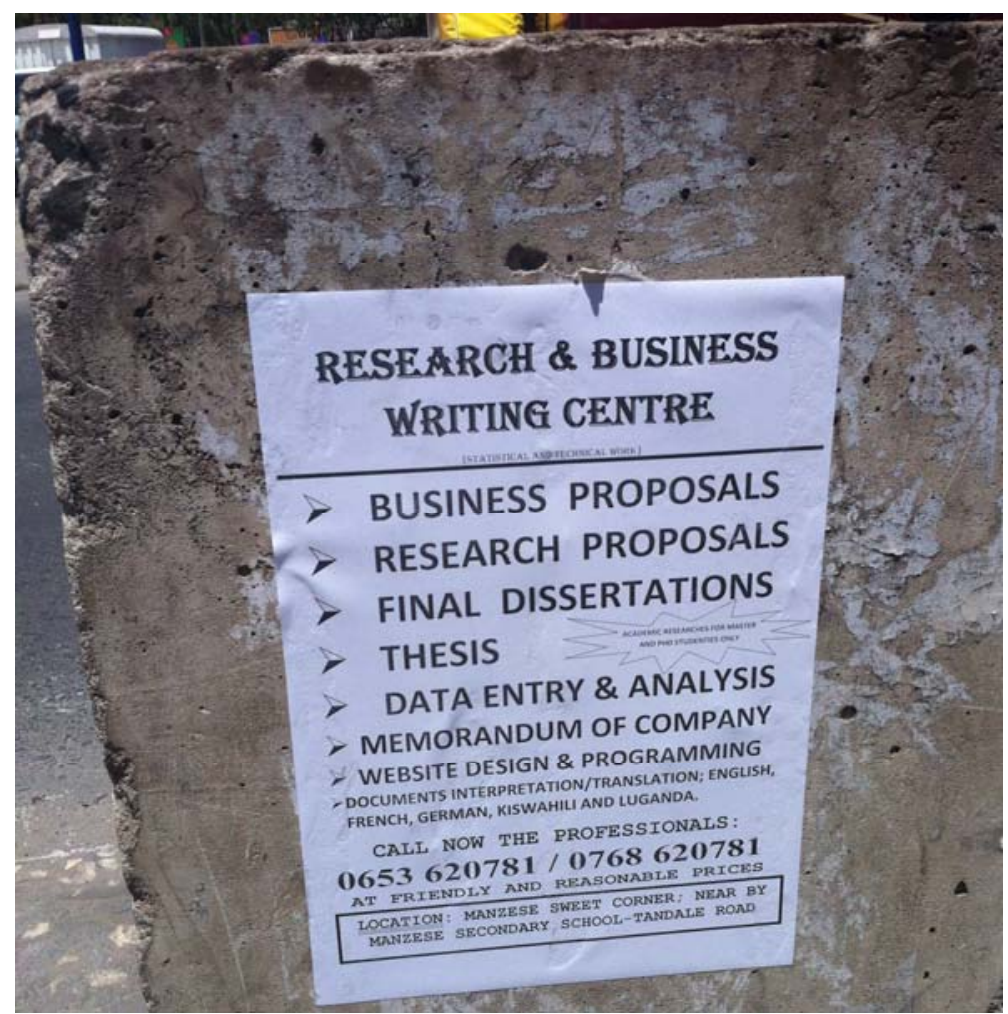

Figure 1. The post advertising for dissertation and thesis writing services and other services available. Source: Field Observation, 2014. 


\section{Funding of Research}

The serious research needs money for effective output. Unfortunately, in Tanzania, research activities are lowly funded and they are not part of the government priority. For instance, the budget for research in Tanzania is less than 1\% of GDP, while country like Japan has invested more than 3.8\% of the GDP in research (URT, 2014). It should be noted that the developing countries have invested very little in research. Tanzania has about 50 high learning institutions, how many of these have research fund? Most of the universities in Tanzania have no allocation of fund for such important activity in academia. Research to many high learning institutions is considered "peripheral activity" and indeed its contribution in teaching is always overlooked.

According to URT (2014), in the 2014/15, Tanzania allocated about 30 million USD for research. In normal practice, however, this fund as other allocated fund will not be disbursed to the end of financial year. The expected little amount of fund which may be even less than half may not be used for the intended activity in the budget time. By contrast, Rutgers University spent about 430 million USD for research in a year (URT, 2014). Therefore, the funding inadequacy in Tanzania leads to the poor performance of research as a process hence its output is invalid and/or incomplete. Thus, such findings become useless for resource management and other related activities.

The situation of limited fund from the government organs has a trickledown effect to individuals. Some researchers have limited funds and in some cases doing a research is a must. In situation like writing of a dissertation/thesis students have to search for fund to fulfil the requirement for an award; because of lack of funding, some students opt to fabricate the findings. One of the students I encountered was honesty to the researcher and stated that:

..... Of course I planned to administer questionnaire 100 respondents in three villages in the study area. I did not make any step outside my village ... I only interviewed 17 people and came back...

This student was not hampered by funding, but the student was not ready to go to the tedious research process. It was noted that in return the supervisor demanded to see the filled questionnaire. The student had to cook the questionnaire over the weekend so as they can be submitted on the followed Monday. This dissertation was accomplished with colourful marks. Moreover, the respondent agreed to have seen others fabricated findings that were caused by budgetary constraints.

Alternative to government fund, there are other funding sources that could foster a research agenda to a great deal. These sources may be offered in terms of grand and commission among others. However, it is evident that sponsoring organs may decide on the methodology to be used. They may sometimes prohibit publication/dissemination of findings or may institute other restrictions. Imposition and acceptance of restriction are unethical as well as in some instances how the information is used by the sponsoring agent is also putting a research into trial. Some agents use it for justification of or a pretext of fostering a management agenda (Babbie, 2005). It should also be noted that in some cases the donor dictates terms and findings by rejecting findings by showing other reports from other places. This situation leads to the cooking of data to suit the donor (Iphofen, 2011).

There are a lot of politics in research development in Tanzania. It was noted that some members of the Parliaments (MP) and others who intend to contest in different posts commission a research and end up in fabricating the findings or using the findings for unethical agenda. There one researcher was also faced by one of the MPs for such purpose. This is not the new thing in Tanzania. In natural resource management, the 
conservation of Rufiji delta is among of the activities where the research was used as a pretext of fostering a certain agenda; refer to Makuadi wa Soko Huria by Chachage Seithy Chachage. It was clear that some researchers were seen as instigators by the state only because they were ethical and principled (Shivji \& Ally, 2012).

There are also a lot of researches done by NGOs and other research institute and individuals where research findings are fabricated to suit the interest of the NGO and sometimes interest of donors. It is totally unethical to use a method you know to be inappropriate to prove or disapprove something that you want to know, for example, selecting highly biased sample using an invalid instrument, or by drawing wrong conclusions (Kumar, 2012). There is a mushrooming number of NGOs in Loliondo Game controlled area and Ngorongoro district in general. It is said that researches which are done in Ngorongoro are fabricated to suit the commercial conflicts that are championed by the west. Some NGOs that have interest in business are supported by Oxfam Ireland (Manyerere, 2013). Oxfarm is said to fund NGONET (Ngorongoro NGO's Network), PINGOS (Pastoralists Indigenous Non-Governmental Organisations) and Ujamaa Community Resource Trust (U-CRT). Nevertheless, some of the NGOs are directly funded by Sokwe Asilia and Rubin Hurt Safaris; NGONET through Tanzania Natural Resources Forum (TNRF), while Dorobo Tours and Safaris funds U-CRT and PWC (PricewaterhouseCoopers). It is also said that NGOs present the politics and business struggles. Again, it is said that the conflicts are due to search for control of resources in Ngorongoro between American and European firms on one hand and Asian firms on the other.

These NGOs are also accused by some of the respondents that they fabricate findings in order to either exaggerate the intensity of the problem for the purpose of attracting more resources from donor agencies. Sometimes may reduce the problem in order to justify to the donors that previous funding was rationally used and the interfered problem was progressively declaiming. This also calls for more funds either for the same problem or for the new one.

\section{Researcher and Politics}

Some of the researchers are not objective; their projects, in most cases, are conducted to propagate a specific agenda. Many research designs involve a degree of deception of subjects. Deceiving people and violate common standards of ethical behaviour. Deception in research requires a strong justification and even then the justification may be challenged (Babbie, 2005).

It should be noted that even science is guided by politics/ideologies. Some people suffer and others die from research as well. A critical research is a revolutionary activity. It is the activity of committing class suicide to attain real findings for the greatest happiness of the greatest number of people (Shivji \& Ally, 2012) It was noted that some researchers do embrace the status quo simply, because either the development agenda is geared by a certain ideology which is contradictory to the real situation. In some situations, researchers fear to challenge the government and therefore, research findings cannot work. On the other hand, Government may force researchers to produce certain findings directly. "Directly" may involve funding and instituting what is required by government. Indirectly may be by challenging all findings which are against the interest of the state followed by persecution of researchers or funding other researchers who will provide the contrast. When the latter technique has been employed, the community will never believe the researchers; and, in fact, researchers and government will be seen as one. This leads to the rejection of research and researchers that will come in the area. 
It was revealed in Namawala village that people did not want to give out land for any investment. The district officials interrupted the village decision in favour of Rufuji Basin Development Authority (RUBADA), Sugar Development Co-operation (SUDECO) and other investors by employing surveyors of land (Haulle, 2014b). This led to emergence conflicts relating to land issues and imprisonment of village officials to the extent that even land use planning is not done to date.

We know SUDECO deals with sugar management but not farming, how come today SUDECO needs to cultivate sugarcane? What is behind this search of our own land? We don't need any intruder here even those who wrote you a letter (Research Clearance) know it very well, that is why they called Village Officer to their Office so as not to see such confrontation”..... One man was speaking to the research team.

In the same spirit: "In short what you want is not possible here! Nobody will be interviewed"... Another responded to the team.

In relation to previous action of either researchers or other government entities, people become nervous; and, therefore, their participation in research was questionable. For instance, it was noted that when the LHRC (Human Rights Centre) researchers arrived in the Olerien-Magaiduru village in Loliondo Division of Ngorongoro district, some of the villagers ran away thinking the Field Force Unit was back to harass them (Haulle, 2014). This happened after the visiting of some officials who collected some data and thereafter evicting some people from the game controlled area which is said to be under the Ortles Business Company (OBC). In some cases, the conflicts over resources caused prohibition of any research in the community. Researchers were seen as instigators. This situation was also reported by researchers who worked within Loliondo Game Controlled Areas as well as those who visited Namawala in Kilombero District.

According to Greenfield (2002), in some cases, a research may be fed by false data from the government to faster a certain agenda. Such data include inflation, economic growth and performance of students. This is because there is no official code of conduct about "Official Data". Some of unfavourable statistics may be browsed from the mass, changing definition discrediting authors of unfavourable research reports. Such findings will not be believed by the community members even the academia. The objective of the state for this matter is to maintain the status quo.

They edited the opinion poll results, they noted that the existing leader was rated low for their safety; they decided to fabricate the results hence showed the other prospective candidate was leading.

For example, the villagers in Namawala rejected researchers who were actually objective. These researchers selected that village among others in Rufiji river basin after having prior information relating to their conflicts. This intended to know how they define their resources and what the causes of the conflicts were over resources in the area. On top of that, this area was chosen, because it was rich in soil nutrients and many are attracted to this basin. The researchers were chased, because they were conceived to play similar role as government and unethical researchers.

We don't want to listen to you; we are not ready to speak to you, because all of you are one and the same. You want to record us and after your departure FFU [Field Force Unity] will come to harass us.

\section{Feedback}

Social researchers have ethical obligations to community of researchers as well as to respondents or subjects. These obligations include provision of feedback fully and accurately as well as disclosing errors, 
limitations and other shortcomings (Babbie, 2005). Dissemination of researcher findings is an important component of any research. Proper feedback is required to provide sense of ownership and acceptance. This is important, because in natural resource management, the villagers may use such findings in planning for Wildlife Management Areas (WMAs), land use and water access and utilisation.

It was noted that some researchers got little support due to limited or failure of feedback system. Some researchers do not provide the feedback to the respondents and targeted community. The study found out researchers powerless, and therefore, researchers are seen as puppets, passive and helpless to the target community.

\section{Conclusion and Recommendations}

Resources are at risk. Management of resources is questionable, because proper and concrete management approaches are not informed by serious research. The management approaches are falsified as their findings are fabricated, cooked and unrealistic. Researchers are seen as politician tools for subornation and control against the mass and those few who are against the state are seen as instigators and petty academics. If the government decisions could be guided and be informed by the scientific studies, the number and intensity of conflicts could have been minimised. Such decisions that will be obtained through participatory approaches while the community members would have information of research findings through the feedback of the research ultimately sound decisions will not be conflicting with other human and livelihood systems. Community peace and security is put into trial when research is unethical and participation of people in resource management is set in periphery. Trust of researchers is steadily declining. Thus integrity of researchers is questionable. Nevertheless, the conflicts over resources may cause genuine research to be prohibited or cause researchers be fed by false data. In some cases, the researchers seem to be pacified for personal agenda.

It is recommended that there is a great need to improve research methods of researchers. Research methods need to be taught rigorously in order to build capacity of researchers tools employed, and principles to be adhered. Nature of the community and its associated problems can only be resolved by the improvement of the capacity of the researcher to know the nature of respondents and their background. When researchers will be well acquainted with research knowledge; ethics and essence of research in the socio-economic setting; studies will be scientific and objective. From this situation, the community will be aware of the importance of research and hence conflicts and politics over resource management will be minimised hence sustainable development.

Furthermore, there is a need to build the culture of truth and integrity. Emphasis should perform a research as a process and expertise. An independent researcher ethics adherence unit needs to be established and strengthened to foster research agenda which is bias free. The Government needs to improve research funding. Proper funding would reduce cheating in research and thus integrity will be improved. Similarly, the participatory planning with improvement of democracy will spur information and more rejection of researchers will be reduced at the great extent.

Again, Government officials need to be informed that researcher is an independent process; and, therefore, does not need any interference. Researchers need to be free from biases and interference. Researchers need to stand firmly on objectivity and principles in order to make the research work for the community. It should be born into the mind that research as an activity and a process is a struggle from improvement of human practice and knowledge. 


\section{References}

Babbie, E. (2005). The basics of social research. Toronto: Thomson Wadsworth.

Bryman, A. (2004). Social research methods (2nd ed.). Dar es Salaam: Oxford Press, London.

Denzin, N. K., \& Lincoln, Y. S. (2013). The landscape of qualitative research. Newdelhi: SAGE Ed, SAGE Publication.

Greenfield, T. (Ed.). (2002). Research methods for postgraduates (2nd ed.). London: John Wiley.

Haulle , E. ( 2014). Assessment of communities coping mechanisms to geodisasters in the vicinity of Oldoinyo Lengai (Ph.D. thesis, University of Dar es Salaam).

Haulle, E. (2014). Land resource in Tanzania; whose state, whose resource?. Fourth International Conference on State, Natural Resources and Conflicts: Actors and Dynamics, August 2014, Maputo.

Iphofen, R. (2011). Ethical decision-making in social research: A practical guide. London: Palgrave Publication.

Kumar, R. (2012). Research methodology: A step by step guide for beginners (3rd ed.). London: SAGE Macmillan.

Manyerere, J. (2013). Bila Kudhibiti NGOs Loliondo Haitatulia. Retrieved from September 12, 2014 http://www.wavuti.com/4/post/2013/04/bila-kudhibiti-ngos-loliondo-haitatulia-manyerere-jackton.html\#ixzz2R20iqAyb

Moshy, V. L. (2006). The role of traditional environmental knowledge systems in resources management in Tanzania: A case of Mbweni Ward, Dar es Salaam, Coastal Unpublished (M.A. Dissertation, University of Dar es Salaam, Dar es Salaam).

Mwanje, J. I. (2001). Issues in social science research: Social science research methodology series module 1. Addis Ababa: OSSREA.

Punch, K. (2012). Introduction to social research: Quantitative and quantitative Approach (2nd ed.). London: Sage Publication.

Shiviji, I. G., \& Ally, B. (2011). Insha za Mapambano ya wanyonge, Taasisis ya Taaluma za Kiswahili (Essays on the Struggles of the Weaklings, Institute of Kiswahili Studies). Dar es Salaam: University of Dar es Salaam.

United Republic of Tanzania (URT). (1997). The mineral policy of Tanzania, ministry of energy and minerals. Dar es Salaam: Ministry of Energy and Minerals.

United Republic of Tanzania (URT). (1998). The Wildlife Policy of Tanzania, Ministry of Natural Resource and Tourism.

United Republic of Tanzania (URT). (2014). Keynote Address by His Excellency Jakaya Mrisho Kikwete, President of The United Republic of Tanzania on Importance of Creating International Collaborative Partnerships for Solving Global Challenges Delivered at Rutgers University, State University of New Jersey, 26th September, 2014, New York in http://www.ikulu.go.tz/index.php/media/speech/1056 accessed on 13 January 2015.

Wills, V. C. (2002). Marx and morality (Ph.D. dissertation, University of Pittsburgh, German). 